\title{
Diarium Saúde: um aplicativo para o enfrentamento da covid-19.
}

\author{
Estrela Gabriela de Araujo', Josué Araújo Moreira', Mellory Mayrtha Lobo \\ Nascimento $^{1}$, Vinícius Brito Bandeira ${ }^{1}$, Antonio Marcos Cardoso Silva ${ }^{2}$, \\ Wanderson Alexandre da Silva Quinto ${ }^{2}$ \\ ${ }^{1}$ Estudantes da Faculdade de Tecnologia em Analise e Desenvolvimento de Sistemas da \\ Universidade do Estado do Pará (UEPA). \\ 2 Professores da Universidade do Estado do Pará (UEPA). \\ Caixa Postal 15.064 - 66.050-540 - Belém - PA - Brasil. \\ \{estrela.araujo, josue.moreira,mellory.nascimento, vinicius.bandeira\}@al \\ uno.uepa.br; \{amarcos,w.quinto\} @uepa.br
}

\begin{abstract}
The popularization of ICT's has been strengthening health support strategies, causing the development of health-related applications to evolve rapidly, enabling new potential for this area. This work is about a technological production research with qualitative methodology for the development and evaluation of an application that took place in the period of 2 months (from March to May 2020). The results showed a reasonable acceptance by users, with the greatest highlight being the function of sharing a report, as the patient who needs care can, with simple actions, send them to the health team.
\end{abstract}

Resumo. A popularização das TIC's vem fortalecendo as estratégias de apoio a saúde, fazendo com que o desenvolvimento de aplicativos relacionados à saúde evoluísse rapidamente, possibilitando novas potencialidades para este setor. Este trabalho trata-se de uma pesquisa de produção tecnológica com metodologia qualitativa para o desenvolvimento e avaliação do aplicativo ocorrida no período de 2 meses (entre março e maio de 2020). Os resultados mostraram uma aceitação razoável pelos usuários, sendo que o destaque maior foi para a função compartilhar relatório, pois o paciente que precisa de atendimento pode com simples ações enviá-los para a equipe de saúde.

\section{Introdução}

No fim do ano de 2019, o mundo foi surpreendido por uma doença emergente, que surgiu na China. A Organização Mundial de Saúde (OMS) explicou que se tratava de um novo tipo de corona vírus (chamado cientificamente de SARS-CoV-2) que tem alto poder de disseminação, fato que fez a OMS declarar em 12 de março de 2020, que a doença havia se tornado uma pandemia.

$\mathrm{O}$ alastramento da pandemia fez com que diversos protocolos fossem adotados em todo o mundo, sendo consensual que a prática do isolamento social é a melhor maneira de conter ou frear o alastramento da doença. Pessoas passaram a trabalhar em sistema home office e a utilizar com mais frequência os aparatos tecnológicos disponíveis. Para Lévy (2004), a aceleração da virtualização é uma tendência irreversível que deve ser integrada às decisões, pois fazem parte do cotidiano da sociedade contemporânea. Segundo Quinto e Silva (2019), o uso de alguns aplicativos de saúde pode se tornar uma ferramenta terapêutica no cuidado, proporcionando autoestima, sentido de pertencimento 
ao mundo atual digital, expressão de sentimentos e interrelação com outros usuários da aplicação como por exemplo, profissionais de saúde.

Jornais locais e nacionais noticiam o colapso do sistema de saúde, pacientes e acompanhantes chegam em alguns casos sem condições de relatar o que estão sentindo, o que tomaram de medicamentos e como passaram nos dias anteriores ao atendimento médico. Fato que atrapalha a compreensão total do que envolve o quadro, sem contar que obscurece na tomada de decisão sobre qual tratamento deve ser realizado de maneira que o paciente possa acusar melhoras mais rápidas e eficazes.

Diante destas problemáticas, este projeto se propôs a desenvolver o Diarium Saúde, um aplicativo fortemente acoplado a critérios de usabilidade em acordo com as Heurísticas de Usabilidade de Nielsen (2003) no formato de diário virtual, para que os usuários possam registrar, acompanhar e compartilhar os dados históricos do seu cotidiano em meio a sinais e sintomas da doença.

\section{Passos Metodológicos}

Trata-se de pesquisa de produção tecnológica para o desenvolvimento e avaliação de aplicativo com vistas a proporcionar tanto para o usuário, quanto a equipe de saúde uma ferramenta que possibilite: o compartilhamento de informações sobre o estado de saúde do usuário do app, com métricas e gráficos. Esta pesquisa ocorreu em quatro fases, na seguinte ordem: pesquisar, relacionar, desenvolver e avaliar. $\mathrm{Na}$ fase de pesquisar, buscou-se não só o referencial teórico, mas também o estado da arte acerca da identificação e caracterização dos métodos de usabilidade.

A fase do relacionar iniciou-se comparando vários processos de design de produtos propostos por diferentes autores visando estabelecer um processo genérico de projeto de produto (telas e funcionalidades) para que fosse desenvolvido e avaliado. Ainda nesta fase foi feita a seleção dos perfis de usuários para a avaliação do app, estes perfis incluíam professores e profissionais de informática experientes em usabilidade, além de equipes médicas multiprofissionais da Universidade do Estado Pará.

A fase do Desenvolver, mantinha dependência cíclica com a fase do avaliar para acompanhar a performance e usabilidade do sistema diante de demandas reais de usuários. Esta fase era composta pelas etapas: Definição da tecnologia utilizada (React Native e duas bibliotecas: o Native Base para componentes visuais genéricos e a React Navigation que ajuda a navegar entre várias telas e compartilhar dados entre elas) e prototipação que são versões incompletas do software desenvolvido.

O protótipo foi submetido a avaliações de usabilidade Nielsen. O tempo de desenvolvimento e testes foi de 2 meses (entre março e maio de 2020). Participaram do projeto de desenvolvimento 3 alunos de iniciação científica e 2 professores orientadores. Quanto as avaliações de usabilidade participaram 2 professores universitários e 1 profissional de informática. 
Os critérios de inclusão para os professores foram de ministrar disciplinas voltadas a área de interface humano computador; para o profissional de informática foi de ter pelo menos 2 anos de experiência em desenvolvimento de software e conhecimento de usabilidade;

Os critérios de exclusão para todos: inadaptação à utilização da aplicação; não ter dispositivo móvel. Quanto ao recrutamento dos participantes foi feito por convite, através de um grupo de whatsapp específico para enfretamento ao Covid da UEPA. Todos os que aceitaram receberam o Termo de Consentimento Livre e Esclarecido e disponibilizado acesso ao aplicativo.

\section{Resultado e Discussão}

O Diarium Saúde apresenta-se como uma estratégia de enfrentamento a COVID-19 e se alinha com os estudos sobre TIC's e saúde como os de Adriano (2017), Quinto e Silva (2019) mostraram que aplicativos que geram informações de saúde e que as adaptam ao perfil do usuário são importantes para influenciá-lo na direção de determinados estilos de vida saudáveis.

O aplicativo possibilita ao usuário informar seu estado de saúde atual (sintomas), e a sua rotina no dia, facilitando o monitoramento diário, como pode ser visto na Figura 1. O usuário pode compartilhar seu histórico de sintomas e rotina com a equipe de saúde, que terá acesso a gráficos que apresentam os sintomas mais recorrentes e as localidades mais visitadas como pode ser visto na Figura 2.

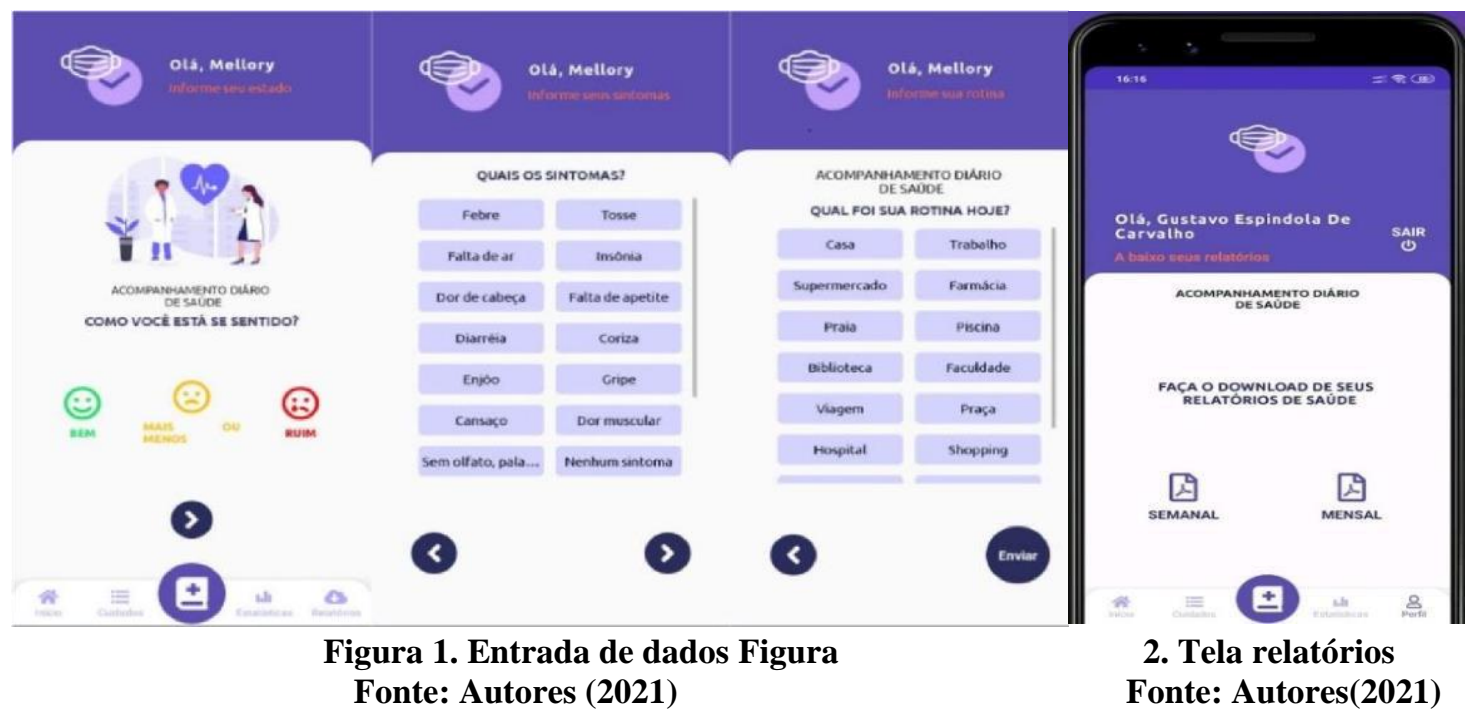

Estas funcionalidades possibilitam traçar estratégias de tratamentos mais eficazes junto com o profissional da saúde. Após o lançamento do Diarium Saúde em 2020, foram feitas pesquisas de aceitação do aplicativo por parte de usuários e equipes de saúde, a saber: $100 \%$ relataram que o app evitou o trabalho repetitivo de levantamento de sintomas, $80 \%$ informaram que os relatórios proporcionaram um feedback mais rápido do quadro geral de cada paciente, $60 \%$ sentiram falta de um espaço explicativo de cada etapa; estes testes utilizaram as heurísticas de Nielsen (2003), que revelaram uma boa aceitação a saber: $80 \%$ relataram que é de fácil navegabilidade e visibilidade de qual parte se está no sistema, $80 \%$ relataram perceber consistência e padrões de telas e ícones, $60 \%$ disseram que o app não informa erros e tiveram que entender sozinhos o que estava acontecendo, 
80\% disseram que o app possui flexibilidade na escolha de opções e eficiência de uso, sendo que o destaque maior foi dado para a função compartilhar relatório que obteve $100 \%$ de aceitação, pois o paciente que precisa de atendimento pode com simples ações enviar para a equipe de saúde seus relatórios. Os fatos evidenciados como negativos serão tratados em adequações futuras que envolvem alterações na interface do aplicativo.

\section{Conclusão}

Como explicado o Diarium Saúde, faz o monitoramento de medicações tomadas, mudanças de humor frequentes ou não, atividades realizadas no dia a dia e relatórios de sintomas. Essas informações são de vital importância para facilitar o atendimento médico, pois vários pacientes tinham alguns sintomas, mas não conseguiam repassar essas informações de forma clara ao chegarem à consulta. Com o Diarium Saúde e os seus relatórios, o diagnóstico tornou-se mais assertivo e rápido.

Percebemos que o usuário precisa entender o propósito do app para que se sinta seguro em utilizá-lo como suporte ao acompanhamento de saúde, fato corroborado por Adriano e Andrade (2017) que destacam o conforto do usuário em ter sua saúde monitorada $24 \mathrm{~h}$ por dia, como função fundamental para pacientes com pressão alta, logo as funcionalidades de um app não favorecem somente os usuários, mas toda a equipe de saúde.

Diante disto ficou claro que o app Diarium Saúde causou impacto positivo no contexto de atendimento e acompanhamento entre médicos e pacientes que participaram dos testes iniciais, pois os mesmos constataram a facilidade e comodidade em poder inserir informações cruciais para o entendimento da enfermidade. O compartilhamento das informações concretas, facilitou em diversas metodologias de implementação de novas medidas de prevenção feitas pela equipe de saúde. Ademais a aplicação no futuro trará relatórios que facilitarão todo o monitoramento do estado ou região, auxiliando autoridades a determinar e focalizar campanhas de saúde.

\section{Referências Bibliográficas}

Adriano O. Andrade, e. a. Novas tecnologias aplicadas a saúde: Integração de áreas transformando a sociedade. 2017. Disponível em

https://www.researchgate.net/profile/AdrianoAndrade3/publication/318649551Nova $\mathrm{s}$ tecnologias aplicadas a saúde integração de áreas transformando a sociedade. Acessos em 20 jun. 2020.

Cates. $\mathrm{O}$ que é tecnologia em saúde. Disponível em http://www.ccates.org.br/areastematicas/avaliacao-de-tecnologias-em-saude. Acessos em 15 jun. 2020 Lévy, Pierre. O que é o virtual? São Paulo, Atlas, 2004.

Nielsen, J. Usability 101: Introduction to usability. 2003

Quinto, Wanderson Alexandre da Silva; Silva, Maria de Nazareth Rodrigues Malcher de Oliveira. O uso de diários virtuais como estratégia de recovery para o encontro tu e eu. Rev. NUFEN, Belém, v.11, n.3, p.45-65, dez. 2019.Disponível em http://pepsic.bvsalud.org/scielo.php?script=sci_arttext\&pid=S2175-

25912019000300005\&lng=pt\&nrm=iso.Acessosem 11 jun. 2020. http://dx.doi.org/ 10.26823/RevistadoNUFEN.vol11.n03artigo58.

Silva JR, Deógenes, Carolina Moreira Oliveira, Ludmilla F. Oliveira Galvão, Jonata da Silva Rodrigues, and Alisson Andrey Puska. "Investigando Heurísticas de Usabilidade no Contexto Móvel de um App de Saúde." Anais Estendidos do XVII Simpósio Brasileiro sobre Fatores Humanos em Sistemas Computacionais, Belém, 2018. SBC. 